\title{
Experimental Investigation on the Properties of Compressed Earth Blocks Stabilised with a Liquid Chemical
}

\author{
Humphrey Danso \\ Department of Construction \& Wood Technology, University of Education, Winneba, Ghana
}

Email address:

dansohumphrey@yahoo.co.uk,hdanso@uew.edu.gh

\section{To cite this article:}

Humphrey Danso. Experimental Investigation on the Properties of Compressed Earth Blocks Stabilised with a Liquid Chemical. Advances in Materials. Vol. 6, No. 6, 2017, pp. 122-128. doi: 10.11648/j.am.20170606.13

Received: September 28, 2017; Accepted: October 10, 2017; Published: November 7, 2017

\begin{abstract}
Soil blocks are usually stabilised with cementing materials, fibres or chemicals to improve their performance properties for construction purpose. This study investigates the properties of compressed earth blocks stabilised with a liquid chemical (Pidiproof LW+). Experiment was conducted using 0.5, 1 and 1.5\% weight contents of Pidiproof LW+ to produce compressed earth blocks and cured at 7, 14, 21 and 28 days. The blocks were tested for density, absorption coefficient, compressive strength and splitting tensile strength. It was found that with the exception of density test, the chemical inclusion in the other tests significantly improved the performance properties of the compressed earth blocks. Furthermore, the higher chemical content (1.5\%) inclusion in the compressed earth block provided better performance properties. The paper concludes that the inclusion of the liquid chemical in the compressed earth blocks generally improved the performance properties of the blocks. Recommendation is made to the use of other chemicals for applicability in earthen construction.
\end{abstract}

Keywords: Compressed Earth Blocks, Density, Absorption Coefficient, Compressive Strength, Splitting Tensile Strength

\section{Introduction}

Stabilisation of soil is the method of adding some materials to the raw soil in order to improve its strength and other performance properties for the purpose of constructing houses. Stabilising a soil is to enhance the properties of the soil irrespective of many weaknesses such as cracking shrinkage, lack of durability, low strength and dimensional instability for housing construction [1]. There are several ways of stabilising soil for housing purposes. Houben and Guillaud [2] identified four main methods of stabilising soil: (1) stabilisation by reinforcement, (2) stabilisation by waterproofing, (3) stabilisation by cementing and (4) stabilisation by treatment with chemicals.

Stabilisation by reinforcement is a method where fibres (natural, synthetic/artificial or Nano) are added to soil to enhance the performance properties. A number of studies [310] have been conducted in the last decade by reinforcement. These studies have reinforced compressed earth blocks with mostly natural and artificial fibres. Another popular method is stabilisation by cementing which is usually done with binders such as cement and lime. This method uses cementing materials such as cement, ash and lime to enhance the performance properties of compressed earth blocks. A good number of research [11-15] have studied compressed earth blocks stabilised with different cementing materials.

However, stabilisation by water-proofing and chemicals have recorded insufficient studies [16-17] in the past and recent times. Balila, et al. [16] studied the properties of adobe bricks stabilised with Bovine serum albumin (BSA) used for the construction of houses. Due to the limited studies conducted on the chemical stabilisation of compressed earth blocks, there is the need to use other potential chemicals to stabilise compressed earth blocks to determine their performance properties for applicability in construction of earthen houses. This study therefore investigates the properties of compressed earth blocks stabilised with a liquid chemical (Pidiproof LW+). The Pidiproof LW+, also known as Dr. Fixit is an additive which is compatible with cement and polymers. It is used to modify the properties of concrete and mortar due to its plastisizing properties that make composite cohesive [18]. It enhances the performance 
properties of concrete and mortar, and meets the requirement of IS: 2645-1983 standard [18].

\section{Experimental Materials and Methods}

\subsection{Materials}

Soil, Pidiproof LW+ and water were the main materials used for the experiment. Soil sample from Ghana was used for the study. The properties of the soil sample used are reported in Table 1. Stabilisation was achieved by using Pidiproof LW+ in the production of compressed earth blocks. The Pidiproof $\mathrm{LW}+$ was obtained at a retail shop for construction materials in Ghana. This chemical is usually used as an additive in cement based composite. The properties of the Pidiproof LW+ according to Pidilite [18] are presented in Table 2. A tap water was used in mixing the soil mortar for preparing the compressed earth blocks.

Table 1. Properties of the Soil Sample.

\begin{tabular}{ll}
\hline Property & Result \\
\hline Proctor test & \\
Optimum moisture content $(\%)$ & 23 \\
Maximum dry density $\left(\mathrm{Mg} / \mathrm{m}^{3}\right)$ & 1.9 \\
Atterberg limits & \\
Liquid limit LL (\%) & 49.2 \\
Plastic limit PL (\%) & 26.9 \\
Plasticity index PI & 22.3 \\
Particle size distribution & \\
Gravel $(>2$ mm) $(\%)$ & 8 \\
Sand $(2-0.063 \mathrm{~mm})(\%)$ & 37 \\
Silt $(0.063-0.002 \mathrm{~mm})(\%)$ & 22 \\
Clay $(<0.002 \mathrm{~mm})(\%)$ & 33 \\
pH & \\
Value & 7.5 \\
\hline
\end{tabular}

Table 2. The Properties of the Pidiproof $L W+[18]$.

\begin{tabular}{lll}
\hline Property & Specification & Result \\
\hline Appearance & - & Free flowing thin liquid \\
Colour & - & Wine red colour \\
Sp. Gravity $@ 25^{\circ} \mathrm{C}(\mathrm{gms} / \mathrm{cc})$ & - & $1.05 \pm 0.02$ \\
Nonvolatile content $(\%)$ & - & $13 \pm 0.5 \%$ \\
pH value & - & $11-13$ \\
Setting time (minutes) & IS: $2645: 1975$ & Initial - 140; Final - 260 \\
Compressive strength $\left(\mathrm{N} / \mathrm{mm}^{2}\right)$ & IS: $2645: 1975$ & Equal to control \\
Chloride content & IS: $2645: 1975$ & $0.002 \%$ \\
Water permeability & IS: $2645: 1975$ & $<50 \%$ of Control \\
\hline
\end{tabular}

\subsection{Preparation of Blocks}

Sixty (60) blocks were prepared and cured for testing. Compressed earth blocks of size $280 \times 140 \times 100 \mathrm{~mm}$ were made with soil and $0.5,1$ and 1.5\% Pidiproof $\mathrm{LW}+$ content by weight. The soil was first spread on a platform, the required quantity of Pidiproof $\mathrm{LW}+$ was added to the water at the optimum moisture content (OMC) (see Table 1), and then the mixture of water and Pidiproof $\mathrm{LW}+$ was added by sprinkling on to the soil and repeatedly turned to obtain a uniform mixture. The blocks were made with BREPAC block making machine (see Figure 1) with a constant pressure of 5 $\mathrm{MPa}$. The blocks were then cured by covering them with a wet jute sack. The jute sack was kept wet throughout the curing period. Three blocks from each mix ratio were randomly selected for testing at 7, 14, 21 and 28 curing days.

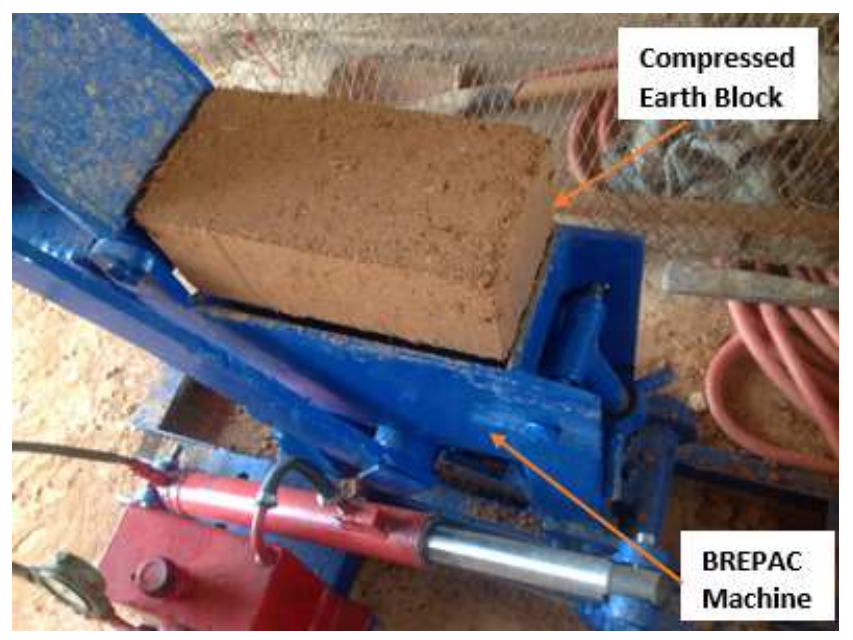

Figure 1. Moulding of Block with BREPAC Machine.

\subsection{Testing of Blocks}

Density of the specimen was determined in accordance with BS EN 771-1 [19]. The blocks were selected and their dimensions measured. They were oven dried at a temperature of $35^{\circ} \mathrm{C}$ after each curing age until a consistent mass was recorded, indicating a normal dried block. The dried blocks were weighed and the density determined.

Water absorption by capillary testing was conducted in accordance with BS EN 772-11 [20]. The blocks were oven dried at a temperature of $35^{\circ} \mathrm{C}$ until a consistent mass was recorded, indicating a normal dried block after 28 days of curing. The mass of the specimens was measured and recorded. The $280 \times 140 \mathrm{~mm}$ bedside of the specimen was immersed to a depth of $5 \mathrm{~mm}$ in a constant head-water bath for $10 \mathrm{~min}$ (see Figure 2). The mass of the absorbed specimen was measured and recorded, and the absorption of water by capillarity rise was then determined.

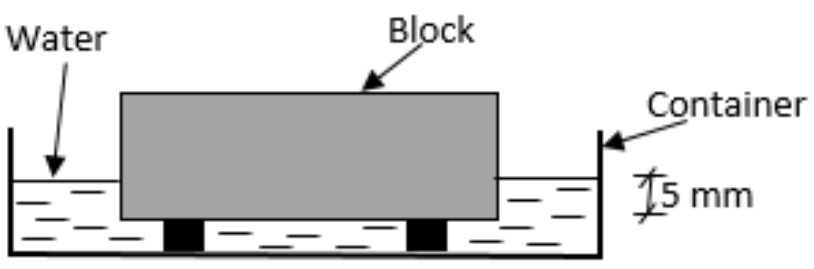

Figure 2. Schematic Set-up for Water Absorption by Capillary.

The compressive test was also performed in accordance with BS EN 772-1 [21]. Testing machine (CONTROLS 50C46G2) with maximum capacity $2000 \mathrm{kN}$, was used (see Figure 3). Loading was applied at a rate of $0.05 \mathrm{~N} / \mathrm{mm}^{2} / \mathrm{s}$ until the block failed. The maximum load applied at which each of the blocks fractured were recorded and the compressive strength of the blocks determined. 


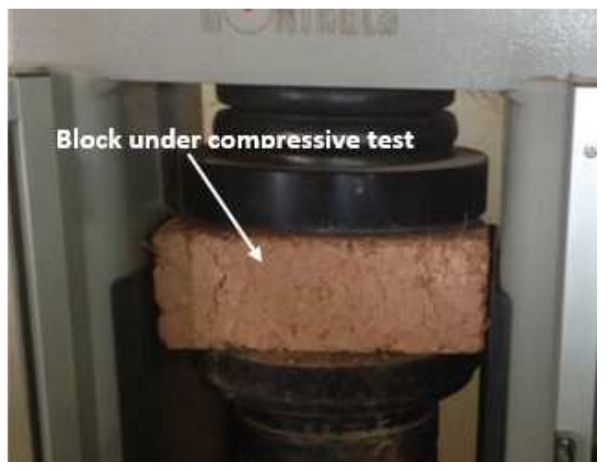

Figure 3. Block Under Compressive Test.

The splitting tensile strength test was performed in accordance with BS EN 12390-6 [22]. This was conducted with the testing machine (CONTROLS 50-C46G2) and splitting jigs were placed centrally above and below the block. The loading was done continuously at a study rate of $0.05 \mathrm{~N} / \mathrm{mm}^{2} / \mathrm{s}$ until the failure of the block. The maximum load applied at which each of the blocks failed were recorded and splitting tensile strength determined.

\subsection{Statistical Analysis}

Correlations were carried-out to establish relationships between the test properties measured. All Pairwise Multiple Comparison Procedure (Holm-Sidak method) was used with overall significance level at 0.05 . One-Way Repeated Measures Analysis of Variance (One-Way RM ANOVA) test and One-Sample t-test with Sigma Plot Version 12 were used to determine the significant difference between the effects of chemical contents and curing age on the compressed earth blocks. Excel 2016 was used to determine the relationship between the compressive strength and tensile strength of the compressed earth blocks.

\section{Results and Discussion}

The detailed test results of the stabilised and unstabilised compressed earth blocks are reported in Table 3. The results include density test, absorption coefficient test, compressive strength test and splitting tensile strength test of the compressed earth blocks tested.

Table 3. Results of the Compressed Earth Blocks Tested.

\begin{tabular}{|c|c|c|c|c|c|c|c|c|c|c|}
\hline \multirow{2}{*}{ Curing (Day) } & \multirow{2}{*}{ Liquid Content (\%) } & \multirow{2}{*}{ Sample } & \multicolumn{2}{|c|}{ Density $\mathrm{kg} / \mathrm{m}^{3}$} & \multicolumn{2}{|c|}{ Comp Str. (MPa) } & \multicolumn{2}{|c|}{ Tens Str. (MPa) } & \multicolumn{2}{|c|}{ Absorption (Coefi.) } \\
\hline & & & Value & Ave. & Value & Ave. & Value & Ave. & Value & Ave. \\
\hline \multirow[t]{9}{*}{7} & 0.5 & 1 & 2021 & \multirow{3}{*}{2039} & 0.98 & & 0.17 & \multirow{3}{*}{0.23} & - & - \\
\hline & & 2 & 2063 & & 1.22 & 1.11 & 0.29 & & - & - \\
\hline & & 3 & 2033 & & 1.12 & & 0.22 & & - & - \\
\hline & 1 & 1 & 2107 & \multirow{3}{*}{2082} & 0.93 & & 0.24 & \multirow{3}{*}{0.27} & - & - \\
\hline & & 2 & 2086 & & 0.99 & 1.01 & 0.29 & & - & - \\
\hline & & 3 & 2054 & & 1.10 & & 0.27 & & - & - \\
\hline & 1.5 & 1 & 1994 & \multirow{3}{*}{2079} & 1.57 & & 0.22 & \multirow{3}{*}{0.28} & - & - \\
\hline & & 2 & 2116 & & 1.31 & 1.40 & 0.29 & & - & - \\
\hline & & 3 & 2128 & & 1.33 & & 0.32 & & - & - \\
\hline \multirow[t]{9}{*}{14} & 0.5 & 1 & 2060 & \multirow{3}{*}{2060} & 1.35 & & 0.29 & \multirow{3}{*}{0.28} & - & - \\
\hline & & 2 & 2098 & & 1.42 & 1.44 & 0.27 & & - & - \\
\hline & & 3 & 2021 & & 1.54 & & 0.27 & & - & - \\
\hline & 1 & 1 & 2063 & \multirow{3}{*}{2063} & 1.60 & & 0.29 & \multirow{3}{*}{0.30} & - & - \\
\hline & & 2 & 2033 & & 1.63 & 1.65 & 0.27 & & - & - \\
\hline & & 3 & 2095 & & 1.72 & & 0.34 & & - & - \\
\hline & 1.5 & 1 & 2054 & \multirow{3}{*}{2026} & 1.71 & & 0.32 & \multirow{3}{*}{0.33} & - & - \\
\hline & & 2 & 2030 & & 1.61 & 1.73 & 0.34 & & - & - \\
\hline & & 3 & 1994 & & 1.86 & & 0.32 & & - & - \\
\hline \multirow[t]{9}{*}{21} & 0.5 & 1 & 2030 & \multirow{3}{*}{1987} & 1.96 & & 0.32 & & - & - \\
\hline & & 2 & 1943 & & 1.77 & 1.87 & 0.34 & 0.33 & - & - \\
\hline & & 3 & 1988 & & 1.89 & & 0.32 & & - & - \\
\hline & 1 & 1 & 2018 & & 1.83 & & 0.32 & & - & - \\
\hline & & 2 & 2152 & 2073 & 1.86 & 1.80 & 0.37 & 0.34 & - & - \\
\hline & & 3 & 2051 & & 1.73 & & 0.34 & & - & - \\
\hline & 1.5 & 1 & 1938 & & 1.97 & & 0.34 & & - & - \\
\hline & & 2 & 1955 & 1943 & 1.80 & 1.91 & 0.39 & 0.37 & - & - \\
\hline & & 3 & 1938 & & 1.97 & & 0.39 & & - & - \\
\hline 28 & 0.5 & 1 & 1988 & & 2.30 & & 0.37 & & 11.29 & \\
\hline & & 2 & 2048 & 2060 & 2.41 & 2.35 & 0.41 & 0.40 & 13.24 & 12.20 \\
\hline & & 3 & 2143 & & 2.33 & & 0.41 & & 12.07 & \\
\hline & 1 & 1 & 2036 & & 2.47 & & 0.44 & & 9.66 & \\
\hline & & 2 & 2113 & 2067 & 2.46 & 2.48 & 0.46 & 0.46 & 10.98 & 10.39 \\
\hline & & 3 & 2054 & & 2.52 & & 0.46 & & 10.51 & \\
\hline & 1.5 & 1 & 2116 & & 2.57 & & 0.51 & & 9.89 & \\
\hline & & 2 & 2128 & 2101 & 2.71 & 2.69 & 0.46 & 0.50 & 8.80 & 8.59 \\
\hline & & 3 & 2060 & & 2.80 & & 0.54 & & 7.09 & \\
\hline & 0 & 1 & 2083 & & 0.83 & & 0.20 & & 14.95 & \\
\hline & & 2 & 2054 & 2052 & 0.94 & 0.92 & 0.27 & 0.23 & 14.95 & 14.67 \\
\hline & & 3 & 2018 & & 0.99 & & 0.22 & & 14.10 & \\
\hline
\end{tabular}




\subsection{Density of Compressed Earth Block}

Figure 4 summarises the density test result of the stabilised compressed earth blocks. The test recorded minimum dry density of $1943 \mathrm{~kg} / \mathrm{m}^{3}$ and maximum $2101 \mathrm{~kg} / \mathrm{m}^{3}$ of the stabilised compressed earth blocks as compared to the average dry density $2052 \mathrm{~kg} / \mathrm{m}^{3}$ of the unstabilised compressed earth block. This indicates that there is not much difference between the dry density of compressed earth blocks stabilised with different liquid chemical contents and different curing days. One-Way RM ANOVA test result ( $p$ value $=0.871)$ between the stabilised and unsatbilised compressed earth blocks suggests that there is no significant difference in the dry density. This means that different contents of chemical inclusion and curing age does not influence the density of compressed earth blocks. This might be attributed to the fact that the chemical used for the stabilisation is a liquid and will not affect the mass of the blocks after drying. This finding is however dissimilar to the findings of cement and fibres used in stabilising soil blocks in previous studies. A study by Arumala and Gondal [23] with cement recorded an increase in density of the stabilised blocks over the unstabilised. This can be explained that the cement acts like a gel and flows into the spaces in the soil reducing the air volume [24-25]. The density of fibre stabilised blocks in previous studies $[8,26]$ was lower than that of the unstabilised blocks. This is possible because the fibres reduce the compact and dense nature of the blocks because the fibres are less dense $[8,31,32]$.

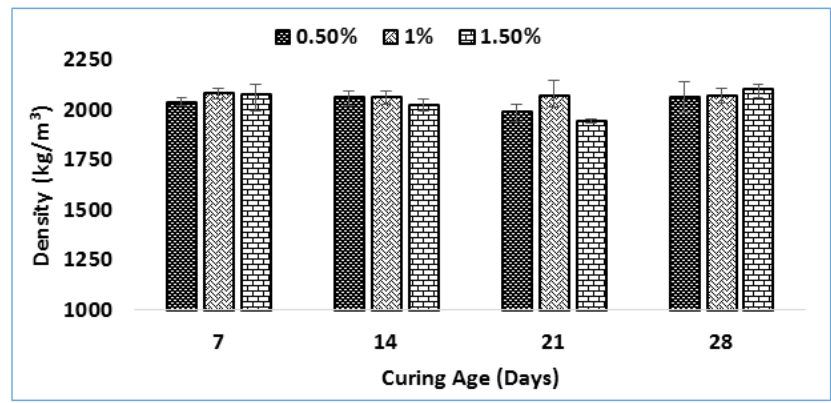

Figure 4. Density Test Result of Stabilised Compressed Earth Block. Error Bars Represent the Range of Data.

\subsection{Absorption Coefficient of Compressed Earth Block}

The absorption coefficient test result is presented in Figure 5. The test recorded an average absorption coefficient of about $15,12,10$ and $9 \mathrm{~kg} /\left(\mathrm{m}^{2} \times \mathrm{min}\right)$ respectively for $0,0.5,1$ and $1.5 \%$ Pidiproof $\mathrm{LW}+$ contents after 28 -day curing. There was about 17,29 and $42 \%$ reduction in absorption coefficient respectively for $0.5,1$ and $1.5 \%$ chemical contents in the compressed earth block as compare to the unstabilised specimen. This implies that the higher the inclusion of the chemical content in the compressed earth block the lower the absorption coefficient. It means that the inclusion of the liquid chemical in the block improved the resistance of water absorption of the blocks. This is in agreement that the use of
Pidiproof $\mathrm{LW}+$ reduce the permeability of water into matrix [18], and therefor functioned similarly in the soil blocks. This can further be explained by the water permeability property of the chemical shown to be $<50 \%$ of the control in Table 2 . One-Sample t-test result ( $p$-value $=0.003)$ between the stabilised and unsatbilised compressed earth blocks suggests that there is significant difference in the absorption coefficient. This suggests that the inclusion of the liquid chemical in the compressed earth blocks significantly improved the water absorption property of the blocks. This is in agreement with previous studies [11, 27-28] with cement which also recorded decrease water absorption of earth blocks stabilised with cement.

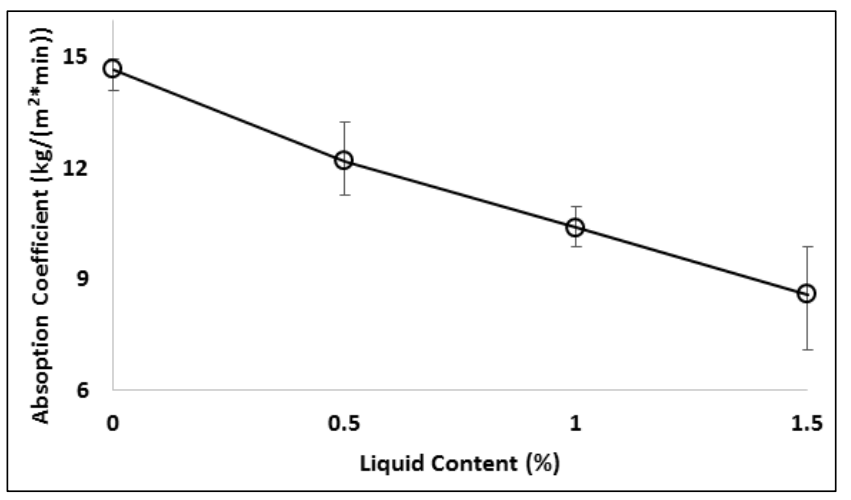

Figure 5. Absorption Coefficient Test Result of Stabilised Compressed Earth Block. Error Bars Represent the Range of Data.

\subsection{Compressive Strength of Compressed Earth Block}

The compressive strength test result as shown on Figure 6 indicates a continuous increase in strength through the curing age for all the liquid chemical contents in the compressed earth blocks. There was more than two times increase in the compressive strength of all the stabilised blocks over the unstabilised compressed earth blocks at the 28-day curing period. This implies that the inclusion of the liquid chemical in the compressed earth blocks increase the compressive strength by curing age. It can also be seen that the higher the chemical content in the block the better the compressive strength of the compressed earth blocks. This is consistent with the results of previous studies [13, 29-30] with cement as stabiliser in soil blocks. The test result of One-Way RM ANOVA ( $p$-value $=0.001)$ for all chemical contents between the stabilised and unsatbilised blocks suggests that there is significant difference in the compressive strength test on the 28 -day curing. Between the $0.5-1.5 \%$ and $1-1.5 \%$ chemical inclusion, there were 0.09 and $0.036 p$-values respectively, however between $0.5-1 \%$ chemical inclusion, there was $0.066 p$-values. This indicate that there was no statistically significant difference between the lower $(0.1-1)$ chemical inclusion, but between the higher and the lower $(0.1$ $-1.5)$, there were statistically significant difference. 


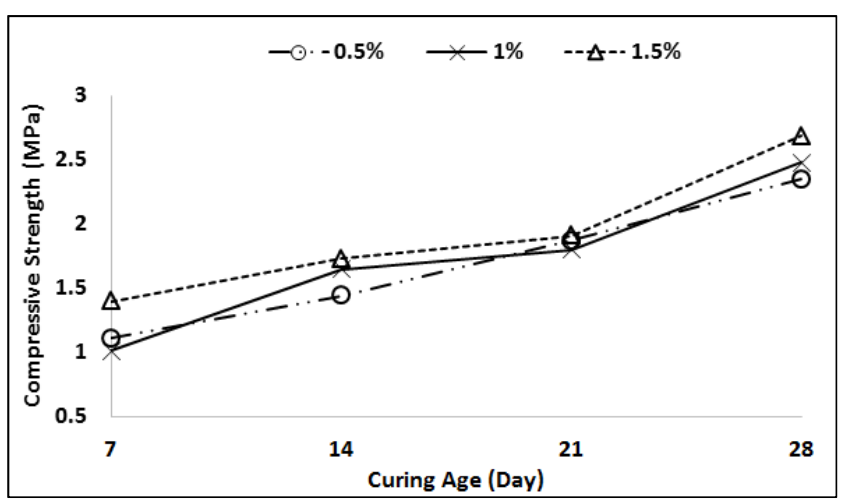

Figure 6. Compressive Strength Test Result of Stabilised Compressed Earth Block.

\subsection{Splitting Tensile Strength of Compressed Earth Block}

The splitting tensile strength result as presented in Figure 7 shows a continuous increase with increased curing age. The average splitting tensile strength of all the stabilised compressed earth blocks was about two times that of the unstabilised blocks. It can also be observed that the higher liquid chemical content $(1.5 \%)$ achieved the higher strength as was also observed in the compressive strength test result in Figure 3. Studies by Bahar et al. [27], Millogo \& Morel [29] and Medjo Eko et al. [30] with cement as stabiliser in soil blocks recorded similar trend. The recorded $p$-values of 0.088 and 0.123 for $1-1.5 \%$ and $0.5-1 \%$ respectively for chemical inclusion shows that there was no significant difference, but the $p$-value of 0.026 recorded for $0.5-1.5$ indicates a statistical significant difference at 28-day curing age. This suggests that the difference between the lowest $(0.5 \%)$ and the highest $(1.5 \%)$ chemical inclusion in the compressed earth block is significant.

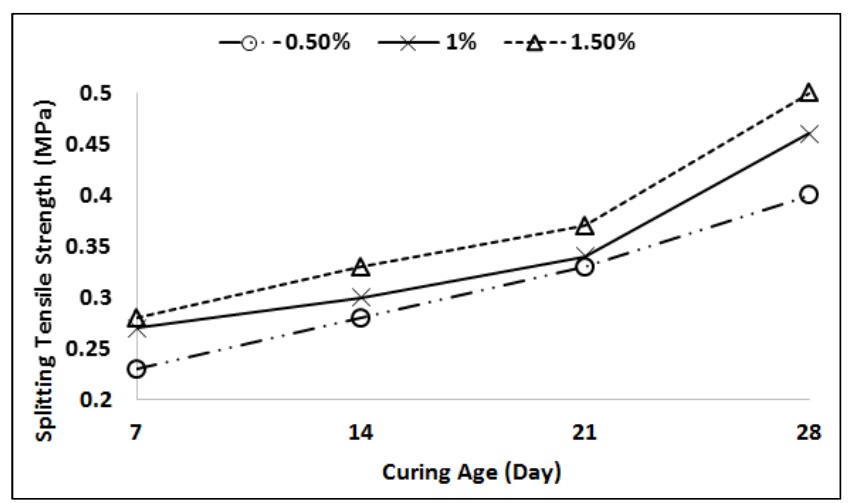

Figure 7. Splitting Tensile Strength Test Result of Stabilised Compressed Earth Block.

\subsection{Relationship Between Compressive and Tensile Strengths of Compressed Earth Block}

The relationship between the compressive and tensile strengths of the compressed earth blocks stabilised with a liquid chemical is presented in Figure 8. It can clearly be seen that there is a very strong positive relationship between the compressive strength and the tensile strength of the blocks. The coefficients determination $\left(R^{2}\right)$ recorded are $0.9977,0.9039$ and 0.9983 for $0.5 \%, 1 \%$ and $1.5 \%$ of the liquid chemical, respectively. This indicates that there was an increased compressive strength of the stabilised compressed earth blocks with increase tensile strength. This results are consistent with previous study which reinforced earth blocks with natural fibres [9].

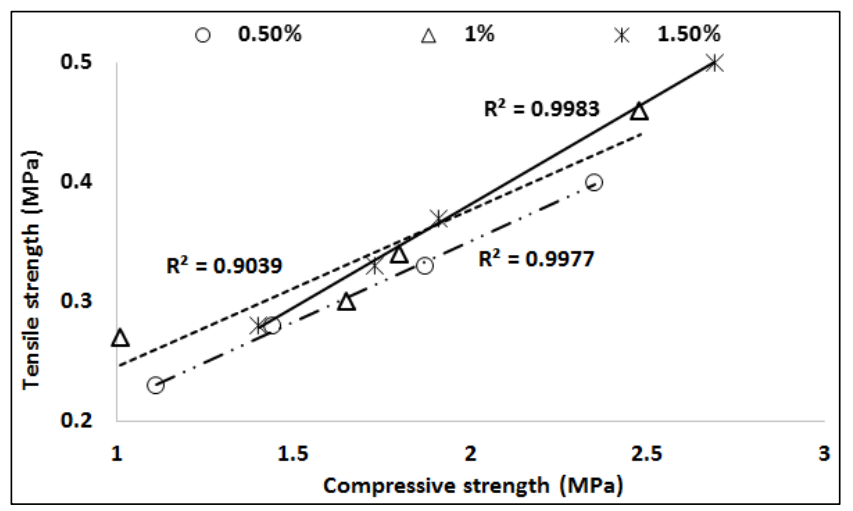

Figure 8. Relationship Between Compressive and Tensile Strengths of Compressed Earth Block.

\section{Summary and Conclusion}

This study presents the properties of compressed earth blocks stabilised with a liquid chemical (Pidiproof LW+). From the basis of the experimental test results obtained, the following concluding summary can be drawn:

1. The addition of the chemical did not significantly affect the density of the compressed earth blocks. This means that the inclusion of liquid chemical does not influence the density of compressed earth blocks.

2. There was significant difference in the absorption coefficient of stabilised and unsatbilised compressed earth blocks. It implies that the inclusion of the liquid chemical in the compressed earth blocks improves the water absorption resistance property of the blocks.

3. It was found that both the compressive strength and the splitting tensile strength of the stabilised blocks doubled that of the unstabilised at the 28-day curing period. This means that the inclusion of the liquid chemical in the compressed earth blocks increase both the compressive strength and splitting tensile strength significantly by curing the blocks.

4. It was also observed that the higher the chemical content $(1.5 \%)$ inclusion in the compressed earth block provided better compressive strength and splitting tensile strength. Correlations test indicated that there was statistically significant difference between the lower chemical content $(0.5 \%)$ and the higher chemical content $(1.5 \%)$ inclusion in the compressed earth block.

5. There was a very strong positive relationship between the compressive strength and the tensile strength of the liquid chemical stabilised compressed earth blocks.

The paper therefore concludes that the inclusion of the liquid chemical (Pidiproof $\mathrm{LW}+$ ) generally improved the 
performance properties of the compressed earth blocks, and the highest performance was achieved at $1.5 \%$ chemical inclusion on 28-day curing. It is recommended that other chemicals used for stabilising concrete and other cement base matrix should be used to stabilised soil blocks to determine their applicability in earthen construction.

\section{References}

[1] H. Danso, Use of agricultural waste fibres as enhancement of soil blocks for low-cost housing in Ghana [Ph.D. thesis], School of Civil Engineering and Surveying, University of Portsmouth, 2015, http://eprints.port.ac.uk/id/eprint/20762.

[2] H. Houben and H. Guillaud, Earth construction: a comprehensive guide. London: International Technology Publications, 1994.

[3] F. Parisi, D. Asprone, L. Fenu, and A. Prota, "Experimental characterization of Italian composite adobe bricks reinforced with straw fibers," Composite Structures, vol. 122, pp. 300307, 2015.

http://dx.doi.org/10.1016/j.compstruct.2014.11.060.

[4] W. Quagliarini and S. Lenci, "The influence of natural stabilisers and natural fibres on the mechanical properties of ancient Roman adobe bricks," Journal of Cultural Heritage, vol. 11, pp. 309-314, 2010. doi:10.1016/j.culher.2009.11.012.

[5] Y. Millogo, J. E. Aubert, E. Hamard and J. C. Morel, "How Properties of Kenaf Fibers from Burkina Faso Contribute to the Reinforcement of Earth Blocks," Materials, vol. 8, pp. 2332-2345, 2015, doi:10.3390/ma8052332.

[6] M. G. Sreekumar and D. G. Nair, "Stabilized lateritic blocks reinforced with fibrous coir wastes" International Journal of Sustainable Construction Engineering and Technology, vol. 4, pp. 23-32, 2013.

[7] P. Donkor and E. Obonyo, "Compressed soil blocks: influence of fibers on flexural properties and failure mechanism," Construction and Building Materials, vol. 121, pp. 25-33, 2016.

[8] H. Danso, D. B. Martinson, M. Ali, and J. B. Williams, "Physical, mechanical and durability properties of soil building blocks reinforced with natural fibres," Construction and Building Materials, vol. 101, pp. 797-809, 2015.

[9] H. Danso, D. B. Martinson, M. Ali, and J. Williams, "Effect of fibre aspect ratio on mechanical properties of soil building blocks," Construction and Building Materials, vol. 83, pp. 314-319, 2015

[10] H. Danso, D. B. Martinson, M. Ali, and J. Williams, "Effect of sugarcane bagasse fibre on the strength properties of soil blocks," in Proceedings of the 1st International Conference on Bio-Based Building Materials, Clermont-Ferrand, France, June 2015.

[11] B. V. Venkatarama Reddy, R. Lal and K. S. Nanjunda Rao, "Optimum Soil Grading for the Soil-Cement Blocks," Journal of Materials in Civil Engineering, vol. 19, pp. 139-148, 2007, doi: 10.1061/(ASCE)0899-1561(2007)19:2(139).

[12] A. S. Muntohar, "Engineering characteristics of the compressed-stabilized earth brick," Construction and Building Materials, vol. 25, pp. 4215-4220, 2011.
[13] R. Alavéz-Ramírez, P. Montes-Garcia, J. Martinez-Reyes, D. C. Altamirano-Juarez and Y. Gochi-Ponce, "The use of sugarcane bagasse ash and lime to improve the durability and mechanical properties of compacted soil blocks," Construction and Building Materials, vol. 34, pp. 296-305, 2012, http://dx.doi.org/10.1016/j.conbuildmat.2012.02.072.

[14] P. Walker and T. Stace, "Properties of some cement stabilised compressed earth blocks and mortars," Materials and Structures, vol. 30, no. 203, pp. 545-551, 1997.

[15] J. E. Oti, J. M. Kinuthia and J. Bai, "Unfired clay bricks: from laboratory to industrial production," Proceedings of the Institution of Civil Engineers, Engineering Sustainability, vol. 162, pp. 229-237, 2009.

[16] A. Balila, M. Vahdati, T. Lees and S. Nortcliff, "Sustainable bio-inspired stabilisers to enhance the strength, durability and structural stability of adobe bricks used for the construction of houses in the outskirts of Khartoum," Young Researchers' Forum III, Innovation in Construction Materials, 12 April 2016.

[17] D. Bernardi, J. DeJong, B. M. Montoya and B. Martinez, "Biobricks: Biologically cemented sandstone bricks," Construction and Building Materials, vol. 55, pp. 462-9, 2014.

[18] Pidilite, "Liquid Integral Waterproofing Compound for Concrete and Plaster," 2010, http://kannanpaints.weebly.com/uploads/3/7/3/7/3737630/pidi proof_lw.pdf.

[19] BS EN 771-1, Specification for masonry units, Clay Masonry Units, European Standard adopted by British Standards Institution:

http://shop.bsigroup.com/ProductDetail/?pid=0000000000301 42472, 2003.

[20] BS EN 772-11, Methods of Test for Masonry Units, European Standards adopted by British Standards Institution: http://shop.bsigroup.com/ProductDetail/?pid=0000000000302 15381, 2011.

[21] BS EN 772-1, Methods of test for masonry units. Determination of Compressive Strength, European Standards adopted by British Standards Institution: http://shop.bsigroup.com/ProductDetail/?pid=0000000000302 $15378,2011$.

[22] BS EN 12390-6, Testing hardened concrete, Tensile Splitting Strength of Test Specimens, European Standard adopted by British Standards Institution: https://www.documentcenter.com/standards/show/BS-EN-12390-6, 2009.

[23] Arumala, J. O. and Gondal, T. Compressed Earth Building Block for Affordable Housing, London, United Kingdom, RICS Publishers. 2007.

[24] H. Danso, B. Martinson, M. Ali, and C. Mant, "Performance characteristics of enhanced soil blocks: a quantitative review," Building Research \& Information, vol. 43, no. 2, pp. 253-262, 2015.

[25] K. M. A. Hossain, M. Lachemi and S. Easa, "Stabilized soils for construction applications incorporating natural resources of Papua New Guinea," Resources, Conservation and Recycling, vol. 51, pp. 711-731, 2007.

[26] C. M. Chan, "Effect of natural fibers inclusion in clay bricks: physico-mechanical properties," International Journal of Civil and Environmental Engineering, vol. 3 (1), pp. 51-57, 2011. 
[27] R. Bahar, M. Benazzoug and S. Kenai, "Performance of compacted cement-stabilised soil," Cement \& Concrete Composites, vol. 26, pp. 811-820, 2004.

[28] K. M. A. Hossain and L. Mol, "Some engineering properties of stabilized clayey soils incorporating natural pozzolans and industrial wastes," Construction and Building Materials, vol. 25, pp. 3495-3501, 2011. doi:10.1016/j.conbuildmat.2011.03.042.

[29] Y. Millogo and J. C. Morel, "Microstructural characterization and mechanical properties of cement stabilised adobes," Materials and Structures, vol. 45, pp. 1311-1318, 2012, DOI $10.1617 / \mathrm{s} 11527-012-9833-2$.

[30] R. Medjo Eko, E. D. Offa, T. Y. Ngatcha and L. S. Minsili,
"Potential of salvaged steel fibers for reinforcement of unfired earth blocks," Construction and Building Materials, vol. 35, pp. $340-346,2012$.

doi.org/10.1016/j.conbuildmat.2011.11.050.

[31] H. Danso, "Properties of Coconut, Oil Palm and Bagasse Fibres: As Potential Building Materials," Procedia Engineering, vol. 200, pp. 1-9, 2017, doi:10.1016/j.proeng.2017.07.002.

[32] A. Laborel-Préneron, J.-E. Aubert, C. Magniont, P. Maillard and C. Poirier, "Effect of Plant Aggregates on Mechanical Properties of Earth Bricks," Journal of Materials in Civil Engineering, vol. 29, pp. 1-12, 2017, doi:10.1061/(ASCE)MT.1943-5533.0002096. 